\title{
EVALUACIÓN DE ELECTROINMUNOTRANSFERENCIA UTILIZANDO ANTÍGENO MIX NATIVO PURIFICADO DE LÍQUIDO DE CISTICERCO DE Taenia solium PARA EL DIAGNÓSTICO DE CISTICERCOSIS HUMANA
}

\author{
Eduardo Ayala-Sulca',a, Eduardo Miranda-Ulloa ${ }^{2, b}$
}

\begin{abstract}
RESUMEN
Objetivos. Evaluar la eficacia de la prueba electroinmunotransferencia (EITB) para la detección de cisticercosis humana utilizando antígeno mix nativo purificado de líquido de cisticerco de Taenia solium. Material y métodos. Estudio observacional de evaluación de prueba diagnóstica. El antígeno mix nativo purificado se extrajo del líquido de cisticerco de cerdos naturalmente parasitados de áreas consideradas endémicas, se evaluó y seleccionó uno de los cuatro métodos de purificación: sulfato de amonio, lecitina de lentejas-sefarosa, Sephadex G-75 y electro-elución. La sensibilidad del antígeno purificado se determinó con EITB y fue evaluada con 50 sueros positivos a cisticercosis y la especificidad con 50 sueros negativos a cisticercosis (20 libres de infección parasitaria y 30 positivos a diferentes parasitosis). Resultados. La concentración óptima del antígeno mix nativo purificado para preparar las tiras EITB fue de $0,82 \mu \mathrm{g} / \mathrm{mm}$. Por cromatografía de afinidad con lectina de lentejassefarosa se visualizaron y purificaron ocho glicoproteínas antigénicas específicas, siendo sus masas relativas de: 13, 14, 17, 18, 23, 24, 31 y $35 \mathrm{kDa}$; los antígenos purificados obtenidos por los otros métodos no fueron evaluados por EITB, porque no correspondieron a las proteínas antigénicas específicas consideradas entre 13 y $35 \mathrm{KDa}$. La prueba de ElTB utilizando antígeno mix nativo purificado presentó $100 \%$ de sensibilidad y $100 \%$ de especificidad. Conclusiones. El antígeno mix nativo purificado mejora la eficiencia diagnóstica de la prueba de EITB. Recomendamos la preparación de un kit in house y su validación en campo para que pueda transferirse e implementarse en laboratorios de zonas endémicas del Perú.
\end{abstract}

Palabras clave: Taenia solium; Cisticercosis; Antígenos (Fuente: DeCS BIREME).

\section{EVALUATION OF ENZYME-LINKED IMMUNOELECTROTRANSFER BLOT TEST USING PURIFIED NATIVE ANTIGEN MIX FROM CISTICERCUS FLUID OF Taenia solium FOR DIAGNOSIS OF HUMAN CYSTICERCOSIS}

\begin{abstract}
Objectives. Evaluate the efficiency of the enzyme-linked immunoelectrotransfer blot test (EITB) for the detection of human cysticercosis using purified native antigen mix from cysticercus fluid of Taenia solium. Material and methods. Observational study of the evaluation of the diagnostic test. The purified native antigen mix was extracted from the fluid of cysticercus from naturally parasitized pigs from areas considered endemic. Four purification methods were evaluated and one was selected: ammonium sulfate, lentil lectin-Sepharose, Sephadex G-75 and Electro-elution. The sensitivity of the purified antigen was determined with EITB and was evaluated with 50 sera positive for cysticercosis and the specificity with 50 sera negative for cysticercosis (20 free of parasitic infection and 30 positive for different parasites). Results. The optimal concentration of the purified native antigen mix to prepare the EITB strips was $0.82 \mu \mathrm{g} / \mathrm{mm}$. By affinity chromatography with Lentil LectinSepharose we visualized and purified 8 specific antigenic glycoproteins, their relative masses being: 13, 14, 17, 18, 23, 24,31 and $35 \mathrm{kDa}$. The purified antigens obtained by the other methods were not evaluated by EITB because they did not correspond to the specific antigenic proteins considered between 13 and $35 \mathrm{kDa}$. The EITB test using purified native antigen mix showed $100 \%$ sensitivity and $100 \%$ specificity. Conclusions. The purified antigen native mix improved the diagnostic efficiency of the EITB test. We recommend the preparation of an in-house kit and field validation so that it can be transferred and implemented in laboratories in endemic areas of Peru.
\end{abstract}

Key words: Taenia solium; Cysticercosis, Antigens (Source: MeSH NLM).

Laboratorio de Referencia Nacional en Zoonosis Parasitaria. Centro Nacional de Salud Pública, Instituto Nacional de Salud. Lima, Perú.

Laboratorio de Referencia Nacional Virus de Transmisión Sexual VIH/ SIDA, Centro Nacional de Salud Pública, Instituto Nacional de Salud. Lima, Perú.

Biólogo-microbiólogo, doctor en Biotecnología; ${ }^{\mathrm{b}}$ biólogo-microbiólogo, magíster en microbiología

Recibido: : 23-01-15 Aprobado: 13-05-15

Citar como: Ayala-Sulca E, Miranda-Ulloa E. Evaluación de electroinmunotransferencia utilizando antígeno mix nativo purificado de líquido de cisticerco de Taenia solium para el diagnóstico de cisticercosis humana. Rev Peru Med Exp Salud Publica. 2015;32(3):485-91. 


\section{INTRODUCCIÓN}

La cisticercosis es una zoonosis parasitaria causada por los quistes larvarios o cisticercos de Taenia solium, que afecta a algunas comunidades de Latinoamérica, Asia y África, de bajos recursos económicos y con bajos niveles de educación lo cual representa un problema de salud pública. En el Perú, la neurocisticercosis (NCC) por $T$. solium es la etiología más común y puede confundirse con otras afecciones del sistema nervioso central y es, además, la causa principal de convulsiones en zonas endémicas del país ${ }^{(1-5)}$.

El diagnóstico de la NCC se hace por medio de la resonancia magnética (RM) o la tomografía axial computarizada (TAC), los cuales constituyen el principal pilar del diagnóstico ${ }^{(6-8)}$. El diagnóstico serológico de la cisticercosis humana es un complemento de mucha utilidad para reforzar los hallazgos radiológicos y clínicos compatibles con esta enfermedad ${ }^{(2-4)}$.

La cisticercosis es erradicable y está considerada dentro de las enfermedades desatendidas ${ }^{(1-5,9)}$. Las pérdidas económicas son altas por el costo horas-hombre que ocasiona la enfermedad (966 dólares por paciente) ${ }^{(10)}$, por la infección de los cerdos con el estado larvario (cisticercosis) lo cual afecta a la calidad y seguridad de la carne de cerdo ${ }^{(11,12)}$, y por el decomiso de la carne porcina parasitada ${ }^{(4)}$.

La prueba de electroinmunotransferencia (EITB) o Western blot, en combinación con antígenos purificados ${ }^{(13)}$ es altamente específico y más sensible que el ELISA o que el examen de la lengua para la detección de infección por $T$. solium ${ }^{(14)}$ en porcinos. En Estados Unidos existe un antígeno purificado por Tsang ${ }^{(13,15)}$ que posee siete glicoproteínas (GP) altamente antigénicas y específicas: GP $50 \mathrm{kDa}$, GP $42-39 \mathrm{kDa}$, GP $24 \mathrm{kDa}$, GP $21 \mathrm{kDa}$, GP 18kDa, GP $14 \mathrm{kDa}$ y GP $13 \mathrm{kDa}$, estas son usadas para el diagnóstico inmunoserológico confirmatorio de cisticercosis. Obregón ${ }^{(16)}$ ha descrito métodos más simples y económicos para aislar GP antigénicas, pero este avance aún no es suficiente para garantizar la producción de estos antígenos a gran escala.

El Ministerio de Salud (MINSA) no cuenta con un kit de diagnóstico serológico de cisticercosis humana; sin embargo, en el Laboratorio de Referencia Nacional de Zoonosis Parasitaria del Instituto Nacional de Salud-Perú (LRNZP-INS), se brinda el servicio con antígeno total, kit in house EITB $(98 \%$ de sensibilidad y $100 \%$ de especificidad) ${ }^{(17)}$. Además, el Laboratorio Escalabs produce un kit comercial CISTIBLOT con una sensibilidad del $91 \%$ y una especificidad del $100 \%{ }^{(18)}$. Ambos kits producen resultados falsos negativos por no tener un $100 \%$ de sensibilidad.
El objetivo del presente estudio es evaluar cuatro métodos de purificación proteica para preparar antígeno purificado obtenidos a partir del Ag.LVC.T.solium y ser implementado con la prueba de EITB.

\section{MATERIALES Y MÉTODOS}

Se realizó un estudio observacional de evaluación de la prueba diagnóstica realizado durante los años 2011-2013. El estudio se desarrolló en cuatro etapas: producción del antígeno nativo total y antígeno purificado; selección del panel de sueros de referencia; evaluación del Ag. purificado con la prueba EITB, y determinación de la eficiencia diagnóstica. El protocolo del estudio fue aprobado por el Comité de Investigación y el Comité de Ética del Instituto Nacional de Salud. A continuación se describen cada una de las etapas.

\section{PRODUCCIÓN DEL ANTÍGENO NATIVO TOTAL Y ANTÍGENO PURIFICADO}

Se seleccionaron cerdos naturalmente parasitados con cisticercosis procedentes de zonas endémicas (Huánuco, Junín, Ayacucho, San Martín, Ucayali y Cajamarca), la selección se realizó mediante el examen de lengua, que consiste en visualizar o palpar los cisticercos en la superficie de la cara posterior de la lengua del cerdo. Este método es relativamente sensible $(87 \%)$ y altamente específico $(99 \%)$ para detectar cisticercosis porcina ${ }^{(13,18-20)}$.

Los cerdos parasitados con cisticercosis fueron sacrificados en el camal de cada zona y luego fueron transportados al Laboratorio de Referencia Regional donde se procedió a la disección de la musculatura, del cerebro, el corazón y la lengua para que queden a la vista los cisticercos y poder obtener el material antigénico.

\section{RECOLECCIÓN Y CUANTIFICACIÓN DEL ANTÍGENO NATIVO TOTAL}

El fluido o líquido vesicular del cisticerco se recolectó con una jeringa de tuberculina estéril, se depositó en un tubo de centrífuga Falcon de $15 \mathrm{~mL}$. Las muestras se conservaron con cubos de hielo $\left(2\right.$ a $\left.8^{\circ} \mathrm{C}\right)$ y protegidos de la luz en caja de poliestireno ("tecnopor").

Los tubos con LVC se centrifugaron a $20114,9 \mathrm{~g}$ por 15 minutos, para separar vestigios de membranas, tejidos y restos celulares. El sedimento de descartó y al sobrenadante se le denominó antígeno nativo total o crudo, este fue extraído asépticamente en tubos rotulados, luego se sellaron, congelaron y fueron enviados al Laboratorio de Referencia Nacional de Zoonosis Parasitaria del Instituto Nacional de Salud (LRNZP-INS). 
En el LRNZP-INS los tubos con Ag-LVC.T. solium total se centrifugaron a $20114,9 \mathrm{~g}$. (centrífuga refrigerada Hitachi: Sorvall Discovery 100SE) por 1 hora a $4{ }^{\circ} \mathrm{C}$ para eliminar componentes lipídicos y otros que puedan interferir en el proceso de purificación. El sobrenadante fue extraído asépticamente y se le agregó inhibidores de proteasas. EI LVC.T. solium nativo total fue utilizado como material antigénico, la cuantificación proteica de cada antígeno se realizó mediante el método Lowry-1951 y se congelaron a $-70^{\circ} \mathrm{C}$ o se liofilizaron para su uso posterior. Estos antígenos se utilizaron para la purificación de las proteínas antigénicas mediante la evaluación con cuatro métodos de purificación proteica.

\section{PREPARACIÓNDELANTÍGENONATIVO PURIFICADO}

Los antígenos nativos totales de mayor concentración fueron descongelados y posteriormente mezclados obteniéndose un Ag.LVC.T. solium mix nativo total. El Ag.LVC.T. solium mix nativo total fue purificado mediante cuatro métodos: sulfato de amonio, cromatografía de afinidad con lectina de lentejas-sefarosa (22,23), Sefadex-G75 y electro-elución. La concentración proteica de cada una de las muestras o lotes (Ag. mix nativo purificado) se determinó con el método de fluorometría.

Las proteínas antigénicas del Ag.LVC.T. solium mix nativo purificados fueron evaluadas por electroforesis en gel de poliacrilamida (SDS-PAGE), coloreadas con azul de Comassie para observar el perfil proteico y la prueba de EITB ${ }^{(24-31)}$ para caracterizar los componentes proteicos según su peso molecular al enfrentar a un control positivo y demostrar la presencia de las bandas reactivas específicas de diagnóstico de la cisticercosis.

La mejor resolución para el Ag.LV.T. solium Huancayo (HCYO.M) total es $1,15 \mu \mathrm{g} / \mathrm{mm}$, para el antígeno total Ayacucho (AYAC) es $0,82 \mu \mathrm{g} / \mathrm{mm}$ y para el antígeno HCYO.L es $0,62 \mu \mathrm{g} / \mathrm{mm}$ (Figura 1)

\section{SELECCIÓN DEL PANEL DE SUEROS DE REFERENCIA}

Las muestras de suero humano como controles (positivos y negativos) fueron seleccionadas de la seroteca del LRNZP-INS. Se seleccionaron por conveniencia 100 sueros humanos y se distribuyeron según se muestra en la Tabla 1.

- Cincuenta sueros positivos a cisticercosis: procedieron de pacientes con cisticercosis confirmada por dos pruebas de imágenes (resonancia magnética o RM y tomografía axial computarizada o TAC), también fueron confirmadas por serología (prueba EITB con Ag.LVC.T.solium nativo total), consideradas en el estudio como gold estándar o de referencia.

- Cincuenta sueros negativos a cisticercosis: veinte sueros procedieron de personas sanas (confirmadas con RM, TAC y serología EITB negativos a NCC) y treinta procedieron de pacientes sin cisticercosis y/o con otras parasitosis (hidatidosis 10, fasciolosis 5 , chagas 5 , toxoplasmosis 5 y leishmaniosis 5 ). Todos los sueros (controles negativos) fueron de personas procedentes de zonas no endémicas a cisticercosis.

Finalmente, se evaluó la presencia de las bandas de precipitación diagnósticas específicas de interés del antígeno purificado y se compararon con las bandas del antígeno total o Ag.LVC.T.solium nativo purificado y total.

\section{EVALUACIÓN DEL Ag. PURIFICADO CON LA PRUEBA EITB}

\section{PREPARACIÓN DE TIRAS EITB}

El Ag.LVC.T.solium mix nativo purificado se mezcló volumen a volumen con solución de tratamiento y

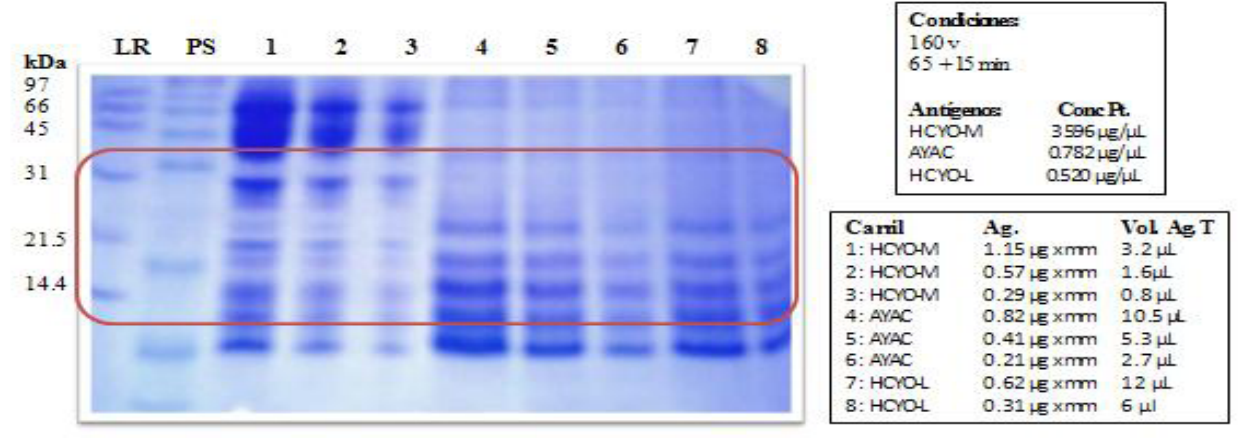

Figura 1. Perfil electroforético del antígeno de cisticerco de Taenia solium 
colorante marcador de corrida para antígeno (Manual LRNZP-INS) ${ }^{(17)}$. Este antígeno tratado fue evaluado para la separación de las glicoproteínas en geles de poliacrilamida (perfil proteico) para determinar la concentración óptima que sirvió para preparar las tiras. Las tiras EITB de $2 \mathrm{~mm}$ de ancho fueron preparadas, primero, mediante electroforesis en geles SDS-PAGE al $17 \%$, y luego mediante electrotransferencia a las membranas de nitrocelulosa de $0,2 \mu$ de porosidad.

\section{PRUEBA DE EITB}

Las tiras de nitrocelulosa impregnadas con Ag.LVC.T.solium mix nativo purificado se incubaron en solución buffer fosfato $\mathrm{pH}$ 7,2 o PBS/tween ${ }_{20}$-leche (PBS.T.L) con los sueros de referencia, a la dilución $1 / 100$, cada uno por canal de la placa de incubación a la temperatura del ambiente por una hora en agitación constante. Se lavaron por cinco veces con $1 \mathrm{~mL}$ de PBS/Tween $_{20}$, luego se agregó el conjugado (anti-IgG humana ligada a una peroxidasa) a la dilución 1/1000 en PBS.T.L y se incubaron en agitación a temperatura del ambiente. Se lavaron como en el paso anterior con PBS.T, y una vez con PBS. Las tiras se incubaron en solución de sustrato (diaminobencidina a 0,5 mg/ $\mathrm{mL}$ en PBS más peróxido de hidrógeno-30\% a 0,01\%) por 5 a $10 \mathrm{~min}$, para visualizar la precipitación de las bandas diagnósticas específicas. Finalmente, las tiras se lavaron con agua destilada para detener la reacción, se secaron y pegaron ordenadamente en una hoja para el análisis e interpretación de la lectura de los resultados.

El resultados se considera positivo si aparece, al menos, de una las ocho bandas diagnósticas específicas que se encuentran entre 13 y $35 \mathrm{KDa}$. (13, 14, 17, 18, 23, 24, 31 y $35 \mathrm{kDa}$,); se considera negativo si no aparece ninguna de ellas.

\section{DETERMINACIÓN DE LA EFICIENCIA DIAGNÓSTICA}

El análisis estadístico de la determinación del rendimiento diagnóstico de la prueba de EITB utilizando Ag.LVC.T.solium mix nativo purificado se realizó mediante la sensibilidad y especificidad.

\section{RESULTADOS}

Los antígenos de LVC.T. solium nativos totales cuantificados con mayor concentración proteica, fueron: Junín $(3,6 \mu \mathrm{g} / \mu \mathrm{L})$, Huánuco $(0,937 \mu \mathrm{g} / \mu \mathrm{L})$, Ucayali $(0,806$ $\mu \mathrm{g} / \mu \mathrm{L})$ y Ayacucho $(0,782 \mu \mathrm{g} / \mu \mathrm{L})$.

Las proteínas del antígeno de cisticerco de T. solium, purificados por cuatro métodos, fueron evaluados en geles de poliacrilamida y coloreados con azul de
Comassie y son las siguientes:

i). Sulfato de amonio: no se visualizaron proteínas antigénicas.

ii). Cromatografía de afinidad con lectina de lentejassefarosa: se visualizaron 8 glicoproteínas antigénicas específicas de diagnóstico, siendo sus masas relativas de: $13,14,17,18,23,24,31$ y 35 $\mathrm{kDa}$,

iii). Sefadex G-75: se visualizaron 17proteínas antigénicass siendo sus masas relativas de: 6,10 , $12,13,14,17,18,21,23,24,31,35,42-45,66,95$, 97 y $100 \mathrm{KDa}$.

iv). Electro-elución: se visualizaron 6 proteínas antigénicas siendo sus masas relativas de: 12, 13, 21, 25, 31 y $97 \mathrm{KDa}$.

La concentración óptima del Ag.LVC.T.solium mix nativo purificado por cromatografía de afinidad con lectina de lentejas-sefarosa para preparar las tiras EITB fue de $0,82 \mu \mathrm{g} / \mathrm{mm}$ en gel de poliacrilamida SDS-PAGE $17 \%$. Los antígenos purificados obtenidos por los métodos con sulfato de amonio, Sefadex G-75 y electro-elución no fueron considerados para ser evaluados con la prueba EITB porque las proteínas antigénicas encontradas no correspondieron a las específicas consideradas entre 13 y $35 \mathrm{KDa}$.

La prueba de EITB utilizando Ag.LVC.T.solium mix nativo purificado presento $100 \%$ de sensibilidad y $100 \%$ de especificidad. No se presentaron falsos positivos ni falsos negativos con la prueba de EITB (Tabla 1).

En la Figura 2 se puede apreciar la presencia de las bandas diagnósticas de interés del Ag.LVC.T.solium mix nativo purificado por cromatografía de afinidad con lectina de lentejas-sefarosa: 13, 14, 17, 18, 23, 24, 31 y $35 \mathrm{kDa}$, y también las bandas reactivas del Ag.LVC.T.solium nativo total: $6,10,12,13,14,17,18$, $21,23,24,31,35,42-45,66,95,97$ y $100 \mathrm{KDa}$.

Tabla 1. Prueba de electroinmunotransferencia (EITB) con Kit-Mix Ag.LVC.T.solium nativo purificado frente a sueros de pacientes sanos, con cisticercosis y otras parasitosis

\begin{tabular}{|c|c|c|c|c|c|c|}
\hline \multirow{2}{*}{ Sueros } & \multicolumn{2}{|c|}{ EITB positivo } & \multicolumn{2}{|c|}{ EITB negativo } & \multicolumn{2}{|c|}{ Total } \\
\hline & $\mathrm{n}$ & $\%$ & $\mathbf{n}$ & $\%$ & $\mathbf{n}$ & $\%$ \\
\hline Cisticercosis & 50 & 100 & 0 & 0 & 50 & 50 \\
\hline Hidatidosis & 0 & - & 10 & 20 & 10 & 10 \\
\hline Chagásicos & 0 & - & 5 & 10 & 5 & 5 \\
\hline Toxoplasmosis & 0 & - & 5 & 10 & 5 & 5 \\
\hline Leishmaniosis & 0 & - & 5 & 10 & 5 & 5 \\
\hline Fasciolosis & 0 & - & 5 & 10 & 5 & 5 \\
\hline Sanos & 0 & - & 20 & 40 & 20 & 20 \\
\hline
\end{tabular}




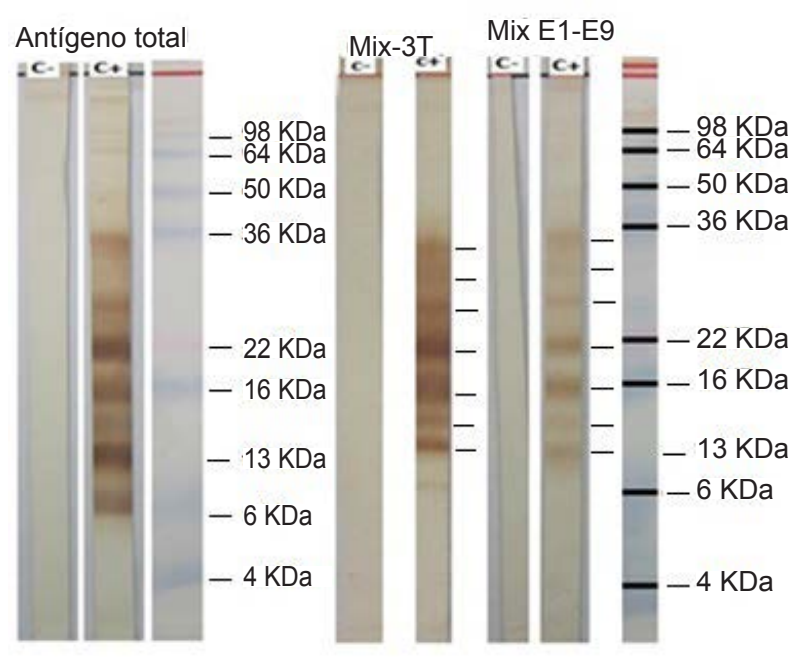

Figura 2. Comparación del Ag.LVC.T.solium nativo total con Ag.LVC.T.solium mix nativo purificado (método cromatografía de afinidad con lectina de lentejas-sefarosa)

\section{DISCUSIÓN}

Los resultados de las concentraciones de los antígenos nativos totales obtenidos en el presente estudio concuerdan con lo reportado en uno de nuestros artículos anteriores, cuyo rango se encuentra entre 0,6 y 3,6 $\mu \mathrm{g} /$ $\mu \mathrm{L}{ }^{(20)}$. La robustez de las concentraciones de nuestros antígenos nativos totales es relevante debido a que condiciona una relación directamente proporcional al antígeno purificado, es decir, a mayor concentración de antígeno nativo total se obtuvo mayor concentración de antígeno nativo purificado. El Centro de Control y Prevención de Enfermedades (CDC), está trabajando con Ag.LVC.T. solium purificado con una concentración proteica entre 3 a $5 \mu \mathrm{g} / \mathrm{mL}{ }^{(14)}$. En este trabajo se ha encontrado una concentración proteica de 3,6 $\mu \mathrm{g} / \mu \mathrm{L}$ en el material antigénico procedente de Junín ${ }^{(20)}$, estas determinaciones están dentro de los parámetros del CDC.

De los cuatro métodos de purificación proteica evaluadas, el método de cromatografía de afinidad con lectina de lentejas-sefarosa mostró mejor rendimiento y fue el ideal para purificar nuestras glicoproteínas de interés. Si bien Tsang del CDC en la prueba de EITB considera siete glicoproteínas (GP) antigénicas específicas: 13, 14, 18, $21,24,39-42$ y $50 \mathrm{KDa}$ para el diagnóstico serológico de neurocisticercosis mediante la prueba de Western blot ${ }^{(13,30)}$; consideramos ocho glicoproteínas antigénicas específicas: 13, 14, 17, 18, 23, 24, 31 y 35 kDa. Estas glicoproteínas referentes fueron consideradas gracias al criterio de positividad que reportaron Escalante et al. ${ }^{(32)}$. Al trabajar con fluido vesicular de cisticerco nativo de Perú frente a sueros peruanos, nuestros resultados estarían adaptándose más a la realidad del país que a la investigación realizada por Tsang. Además, en estudios preliminares hemos demostrado con la prueba EITB que cisticercosis por $T$. solium presenta reacción cruzada con otras parasitosis como Echinococcus granulosus, Fasciola hepatica e Hymenolepis nana en las bandas GP 42-39 KDa ${ }^{(33-35)}$ consideradas bandas inespecíficas. En base a estos resultados decidimos estimar que las bandas específicas de diagnóstico están en el rango de 13 a $35 \mathrm{Kda}$, usando el Ag.LVC.T. solium nativo purificado.

Con antígeno total, las proteínas diagnósticas se identificaron entre $6 \mathrm{KDa}$ y $98 \mathrm{KDa}$. Con antígeno purificado nuestros resultados son similares a los obtenidos por Flisser ${ }^{(26,27,34)}$ y Tsang ${ }^{(13)}$. Al comparar las glicoproteínas diagnósticas de nuestros antígenos purificados se puede observar que los pesos moleculares se encuentran entre GP 13 KDa y GP 35 KDa.

En Colombia, Pinilla et al., utilizando extractos antigénicos a partir de quistes liofilizados de Cisticerco cellulosae reportaron para la prueba de EITB una sensibilidad de $79 \%$ y una especificidad de $89 \%$. Sus proteínas antigénicas específicas más frecuentes fueron de 29,45 y $66 \mathrm{KDa}^{(35)}$, las cuales no concuerdan con las de nuestro estudio. Existen evidencias de que el líquido vesicular del cisticerco constituye la mayor fuente de antígenos del cisticerco de T. solium ${ }^{(30)}$; estos aspectos posiblemente fueron los que causaron la baja eficiencia diagnóstica reportada en ese país.

Actualmente en el Perú, el Hospital de Ciencias Neurológicas utiliza la técnica de EITB con antígenos glicoproteicos purificados, que son cedidos por el CDC de los Estados Unidos. La sensibilidad de esta técnica en pacientes con más de un quiste viable de cisticercosis fue de $98 \%$ y su especificidad fue del $100 \%{ }^{(15,36)}$. Nuestros resultados con antígenos purificados muestran una sensibilidad y especificidad del $100 \%$, parecido a lo reportado por el Cysticercosis Working Group in Peru ${ }^{(12,36)}$ y de mejor eficiencia diagnóstica que la de $91 \%$ de sensibilidad y $100 \%$ de especificidad reportada por Escalante et al. (30). Al purificar los antígenos nativos se ha mejorado significativamente la sensibilidad, esto concluye en una disminución de resultados falsos negativos. También podría mejorar el diagnóstico serológico de cisticercosis humana por EITB en zonas donde la enfermedad es endémica.

Investigadores peruanos prepararon tiras EITB con $0,025 \mu \mathrm{g} / \mathrm{mm}$ de antígeno nativo total ${ }^{(30)}$; nuestras tiras de EITB se prepararon con $0,82 \mu \mathrm{g} / \mathrm{mm}$ de antígeno mix nativo purificado, porque en el proceso de purificación del antígeno total la concentración proteica se diluye. A 
pesar que la diferencia es robusta, la concentración del antígeno purificado no es elevada y se pueden preparar cientos de tiras con el antígeno obtenido en un solo proceso de purificación, siendo factible la preparación inmediata de kits in house y a mediano plazo la preparación de kits comerciales. El Ag.LVC.T.solium mix nativo-purificado se puede preparar, validar y utilizar en países en vías de desarrollo como Perú, realizándose una estandarización previa, además de ser confiable y de costo accesible, siendo una alternativa para el diagnóstico serológico y para estudios epidemiológicos de la neurocisticercosis.

Entre nuestras limitaciones podemos señalar que no fue posible acceder al antígeno purificado de cisticercosis del CDC de Atlanta-USA. Por lo tanto, no fue posible realizar una comparación frente a nuestros antígenos purificados; sin embargo, nos propondremos realizarlo en una siguiente etapa de investigación. Otra limitante involucró a los pacientes con otras parasitosis, a los cuales no fue posible realizarles TAC y RM por no tener accesibilidad a los pacientes, sin embargo, la negatividad está garantizada por ser procedentes de zonas no endémicas a cisticercosis.

Concluimos que el Ag.LVC.T.solium mix nativo-purificado por el método de cromatografía de afinidad con lectina de lentejas-sefarosa podría mejorar el diagnóstico inmunoserológico de cisticercosis humana mediante la prueba EITB. Recomendamos la validación y preparación de un prototipo de KIT y que a mediano plazo pueda transferirse e implementarse a los laboratorios de zonas endémicas de cisticercosis en Perú.

\begin{abstract}
Agradecimientos: a los Biólogos Omar Orellana Diaz, Margarita Zúniga Saca, Alejandro Duran Nieva, Sadith Arévalo Muñoz, Heriberto Arévalo Ramírez, de los Laboratorios de Referencia Regional. A la Bióloga Fabiola Carhuajulca quijano y a la Psicóloga Janina Zenia Ayala Parra. Asimismo, a los médicos veterinarios Juan Vásquez Ampuero y Juan Carlos Carhuamaca Calderón por sus valiosos aportes en las diferentes actividades de la investigación.
\end{abstract}

Contribuciones de autoría: EAS, ha participado en la Concepción y diseño del artículo. EMU y EAS han participado en la recolección de material biológico en las zonas endémicas (con la colaboración de los Laboratorios de Referencia Regional), en la recolección de datos, en el procesamiento y en la redacción del artículo. EAS realizó el análisis de datos, obtuvo el financiamiento y participa en la aprobación de la versión final.

Fuentes de financiamiento: Instituto Nacional de Salud, Ministerio de Salud/Perú

Conflictos de interés: los autores declaran no tener conflictos de interés en la publicación del presente artículo.

\section{REFERENCIAS BIBLIOGRÁFICAS}

1. Sarti E. La teniosis y cisticercosis por Taenia solium. Salud Publica Mexico. 1997;39(3):225-31.

2. Perú, Ministerio de Salud. Teniasis/ cisticercosis por Taenia solium, un serio problema de salud pública en el Perú. Lima: Oficina General de Epidemiología; 2001.

3. Garcia $\mathrm{HH}$, Martinez M, Gilman R, Herrera G, Tsang VC, Pilcher JB, et al. Diagnosis of cysticercosis in endemic regions. The Cysticercosis Working Group in Peru. Lancet. 1991;338(8766):549-51.

4. García HH, Gonzales AE, Gilman RH, Cysticercosis Working Group in Peru. Diagnosis, treatment and control of Taenia solium cysticercosis. Curr Opin Infect Dis. 2003;16(5):411-9.

5. Organización Panamericana de la Salud, Organización Mundial de Salud. Epidemiología y Control de la teniasiscisticercosis en América Latina. Versión 3.0. REF: PNSP/91-28. 1994.

6. Zea-Vera A, Cordova EG, Rodriguez S, Gonzales I, Pretell EJ, Castillo Y, et al. Parasite antigen in serum predicts the presence of viable brain parasites in patients with apparently calcified cysticercosis only. Clin Infect Dis. 2013;57(7):e154-9. doi: 10.1093/cid/ cit422.

7. García $\mathrm{HH}$, Del Brutto $\mathrm{OH}$; Grupo de Trabajo cisticercosis en el Perú. Neurocisticercosis: conceptos actualizados acerca de una enfermedad antigua. Lancet Neurol. 2005;4(10):653-61.

8. García HH, Herrera G, Gilman RH, Tsang VC, Pilcher JB, Diaz $\mathrm{JF}$, et al. Discrepancies between cerebral computed tomography and western blot in the diagnosis of neurocysticercosis. The Cysticercosis Working Group in Peru (Clinical Studies Coordination Board). Am J Trop Med Hyg. 1994;50(2):152-7.

9. Serpa JA, Yancey LS, White AC Jr. Advances in the diagnosis and management of neurocysticercosis. Expert Rev Anti Infect Ther. 2006;4(6):1051-61.

10. Rajkotia Y, Lescano AG, Gilman RH, Cornejo C, García HH; Cysticercosis
Working Group of Peru. Economic burden of neurocysticercosis: results from Peru. Trans R Soc Trop Med Hyg. 2007;101(8):840-6.

11. Gavidia C, Verástegui M, García HH, Urbina T, Tsang VCW, et al. Relación entre anticuerpos séricos y carga de larvas de Taenia solium en cerdos criados en condiciones de campo. PLoS NEGL Trop Dis. 2013;7(5):e2192. doi: 10.1371/journal.pntd.0002192.

12. The marketing of cysticercotic pigs in the Sierra of Peru. The Cysticercosis Working Group in Peru. Bull World Health Organ. 1993;71(2):223-8.

13. Tsang VC, Brand JA, Boyer AE. An enzyme linked immunoelectrotransfer blot assay and glycoprotein antigens for diagnosing human cysticercosis (Taenia solium). J Infect Dis. 1989;159(1):50-9.

14. González AE, Cama V, Gilman RH, Tsang VC, Pilcher JB, Chavera A, et al. Prevalence and comparison of serologic assays, necropsy, and tongue examination for the diagnosis of porcine cysticercosis in Peru. Am J Trop Med Hyg. 1990;43(2):194-9. 
15. Salazar L. Manual de Virología. Lima: Centro Internacional de la Papa; 2008.

16. Obregón-Henao A, Gil D, Gomez D, Sanzón F, Teale J, Restrepo B. El papel de los carbohidratos en la antigenicidad de las glicoproteínas del cisticerco de la Taenia solium. Infect. 2002;6(1)1-12.

17. Perú, Instituto Nacional de Salud. Manual de procedimientos para el diagnóstico serológico de las zoonosis parasitarias. Serie de Normas Técnicas No 32, 2da ed. Lima: MINSA, INS; 2010.

18. Escalante H, Miranda E, Lorca M, Verástegui $\mathrm{M}$, Torres R. La técnica de «Western blot» con antígenos de fluido vesicular de Cysticercus cellulosae para el diagnóstico de la cisticercosis. Lima; 2004.

19. Red de Salud Pública Veterinaria [Internet]. Unión Europea: Sapuvetnet. Taeniasis cisticercosis: una revisión literaria. Disponible en: http://www.sapuvetnet.org/antigo/ Esp_PROC_07.htm

20. Ayala E, Miranda E. Cuantificación proteica del líquido vesicular de cisticerco de Taenia solium. Rev Peru Med Exp Salud Publica. 2014;31(1):175-6.

21. Miranda-Ulloa E, Sandoval-Ahumada $\mathrm{R}$, Ayala E, Vásquez-Ampuero J. Evaluación de las pruebas DOT BLOT y aglutinación de látex para el diagnóstico de cisticercosis en Perú. Rev Peru Med Exp Salud Publica. 2014;31(2):297-301.

22. Taranenko NI, Shukla AK, Shukla MM, Doroshenko VM. Effects of lectins affinity chromatography on glycoproteins enrichment using APMALDI ion trap mass Spectrometry. Proceedings of the 2nd ASMS conference on Mass spectrometry and Allied topics. Nashville: Mass Tech; 2004.
23. Shinit C. Estudios estructurales de lectinas de algas marinas y de vegetales superiores. Tesis para optar el grado de Doctor en Bioquímica y Biología molecular. Universidad de Valencia. Valencia, España. 2007.

24. García Pérez HM. Electroforesis en geles de poliacrilamida: fundamentos, actualidad e importancia. Univ Diag. 2000;1(2):31-41.

25. BIORAD. Mini-PROTEAN ${ }^{\circ}$ II. Electrophoresis Cell. Instruction Manual. California: Life Science Group; 2000.

26. Flisser A, Plancarte A, Ávila G. Aplicación de métodos de diagnóstico de cisticercosis y teniasis a estudios epidemiológicos. En: Taeniasis/ Cysticercosis por T.solium 2da Edición. García HH, Martinez SM ed. Lima: Universo; 1996. p. 17-31.

27. Flisser A, Madrazo I, Delgado $H$. Cisticercosis humana. México, DF: El Manual Moderno; 1997.

28. Diaz JF, Verastegui M, Gilman RH, Tsang VC, Pilcher JB, Gallo C, et al. Immunodiagnosis of human cysticercosis (Taenia solium): a field comparison of an antibody-enzymelinked immunosorbent assay (ELISA), an antigen-ELISA, and an enzymelinked immunoelectrotransfer blot (EITB) assay in Peru. The Cysticercosis Working Group in Peru (CWG). Amer J Trop Med Hyg. 1992;46(5):610-15.

29. Universidad Nacional Mayor de San Marcos, Facultad de Ciencias Biológicas, Laboratorio de biología molecular. Manual de biología molecular. Lima: UNMSM; AÑO????

30. Escalante H, Miranda E, Lorca M, Verástegui $\mathrm{M}$, Torres R. La Técnica de "Western Blot" con Antígenos de Fluido Vesicular de Cysticercus cellulosae para el Diagnóstico de la Cisticercosis. Boletín Peruano de Parasitología. 11:26-31.
31. Levine MZ, Lewis MM, Rodriguez S, Jimenez JA, Khan A, Lin S, et al. Development of an enzyme-Linked Immunoelectrotransfer blot (EITB) assay using two baculovirus expressed recombinant antigens for diagnosis of Taenia solium taeniasis. J Parasitol. 2007;93(2):409-17.

32. Gottstein B, Tsang VC, Schantz PM. Demonstration of specie-specific and cross-reactive components of Taenia solium metacestode antigens. Am.J. Trop. Med. Hyg. 1986;35(2):308-13.

33. Schantz MM, Shanks D, Wilson M. Serologic cross-reactions with sera from patients with echinococcosis and cysticercosis. Am.J.Trop.Med.Hyg. 1980;29(4):609-12.

34. Flisser A, Pérez-Montfort R, Larralde C. The immunology of human and animal cysticercosis: a review. Bull World Health Organ. 1979;57(5):839-56.

35. Pinilla G, Navarrete J, Almonacid C, Bermudez M, Villamil LC. Detección de antígenos dominantes para el diagnóstico de cisticercosis por inmunoelectrotransferencia (Eitb). NOVA. 2003;1(1):44-8.

36. Saavedra H, Gonzalez I, Alvarado M, Porras M, Vargas V, Cjuno R, et al. Diagnóstico y manejo de la neurocisticercosis en el Perú. Rev Peru Med Exp Salud Publica. 2010;27(4):586-91.

Correspondencia: Eduardo Ayala-Sulca

Dirección: Capac Yupanqui 1400-Jesús Maria, Lima, Perú.

Teléfono: (511) 990896186

Correo electrónico: ayalase2001_@hotmail.com 